\title{
Ensino de Língua Portuguesa: aspectos teóricos e metodológicos do ensino de gramática. Uma entrevista com a Professora Heloísa Maria Moreira Lima Salles
}

\section{Entrevistada}

A professora Heloísa Maria Moreira Lima Salles possui graduação em Letras pela Universidade de Brasília, mestrado em Linguística pela Universidade de Brasília e doutorado em Linguística pela University of Wales. É professora associada da Universidade de Brasília. Atua na área de Linguística, na abordagem da Teoria Gerativa, investigando, principalmente, os seguintes temas: sintaxe de complementação e sintaxe de preposições, com ênfase em línguas românicas, germânicas, língua brasileira de sinais, aquisição de português L2, bilinguismo dos surdos.

Entrevista concedida em: 29/05/2017

\section{Entrevistadores}

Lucilene Lisboa de Liz

Doutora em Lingüística pela Univ. Federal de Santa Catarina - UFSC. Professora da Univ. do Estado de

Santa Catarina - UDESC Brasil

lucylisboa@gmail.com

\section{Dalva Maria Alves Godoy}

Doutora em Lingüística pela Univ. Federal de Santa Catarina - UFSC. Professora da Univ. do Estado de

Santa Catarina - UDESC Brasil

lucylisboa@gmail.com

\section{Marco Antonio Martins}

Doutor em Lingüística pela Univ. Federal de Santa Catarina - UFSC.

Professor da Univ. Federal de

Santa Catarina - UFSC

Brasil

lucylisboa@gmail.com

\section{Para citar esta entrevista:}

SALLES, Heloísa Maria Moreira Lima. Ensino de Língua Portuguesa: aspectos teóricos e metodológicos do ensino de gramática. Uma entrevista com a Professora Heloísa Maria Moreira Lima Salles [Entrevista concedida em 29 de maio de 2017]. Revista PerCursos. Florianópolis, v. 18, n.37, p. 182 - 193, maio/ago. 2017. Entrevistadores: Lucilene Lisboa de Liz, Dalva Maria Alves Godoy e Marco Antonio Martins. 
Entrevistadores: Considerando a polissemia associada à noção de "gramática" e, consequentemente, de "ensino de gramática", na literatura corrente, como você define o que é "ensinar gramática" desde os anos iniciais da Educação Básica? Que/quais aspecto/s deve/m ser considerado/s quando o foco é o "ensino de gramática"?

Heloísa Maria Moreira Lima Salles: Em primeiro lugar, gostaria de agradecer a oportunidade de trazer um depoimento à Revista PerCursos, da UDESC, para tratar de questões relativas à educação nacional, pelo ponto de vista do ensino de língua, mais especificamente do ensino da gramática no componente curricular de língua portuguesa. Diante das demandas educacionais de nossa sociedade, é inegável que nós, pesquisadores, docentes universitários, formadores que somos de professores e também atuantes nos programas de formação continuada de profissionais, devemos nos posicionar em relação a tais questões, seja pela experiência agregada no desempenho dessas atribuições, seja por estarmos engajados na pesquisa científica que se dedica a tais questões, produzindo conhecimento e resultados que podem contribuir para o enfrentamento das questões que nos desafiam a cada dia.

Em meu caso, as questões educacionais sempre estiveram presentes na minha reflexão e na minha atuação, sendo a investigação da gramática o recorte pelo qual tenho abordado os inúmeros problemas que se colocam no contexto educacional.

Para tanto, e agora me dirijo especificamente a essa primeira questão que me foi colocada, faz-se necessário estabelecer uma delimitação teórica e epistemológica, o que permite qualificar, por exemplo, a noções de 'gramática', e entender a polissemia a que você se refere.

O trabalho com a língua na escola deve ser entendido como um grande processo, que se inicia na Educação Infantil, e se desenvolve nos 12 anos da Educação Básica. Acho que esse primeiro entendimento, ainda que óbvio, precisa ser considerado objetivamente, para que possamos falar do 'ensino de gramática' - ou seja, trata-se de um processo, que leva tempo e que dispõe desse tempo. Em princípio, considero que o ensino da gramática é inerente às atividades que envolvem o letramento, incluído o processo de alfabetização, passando pelas etapas sucessivas do desenvolvimento da leitura e da escrita. Não há como efetuar tais procedimentos sem que se recorra ao entendimento de 
que os enunciados se estruturam por meio de unidades sistematicamente organizadas, ou estruturadas. A questão é até que ponto o conhecimento a respeito do funcionamento desse sistema é explicitado ao estudante, considerados os objetivos que se tem em cada etapa desse longo processo.

Responder a essa pergunta, de forma a satisfazer a complexidade das questões implicadas, é muito difícil. No entanto, posso adiantar que sou favorável à reflexão sobre a gramática no contexto educacional, cabendo buscar os meios para tornar significativa a relação entre o funcionamento da estrutura gramatical da língua e o desenvolvimento da leitura e da escrita. Nesse sentido, precisamos superar a prática que isola o 'ensino de gramática' do ensino da leitura e da escrita, ou ainda que subtrai o ensino da gramática sob argumento de que as práticas de leitura e escrita são suficientes. Considero que o trabalho com a gramática é inerente a esse processo.

Entrevistadores: Em seu artigo "Educação linguística e ensino de gramática na educação básica", em coautoria com Pilati et all (2011), vocês assumem que a escola deve levar em conta o saber inato que a criança apresenta, no sentido de que alguns saberes devem ser explicitados e não ensinados. Como isso poderia ocorrer no ensino efetivo de gramática de língua portuguesa na Educação Básica, em sua opinião?

Heloísa Maria Moreira Lima Salles: Sim, de fato, já mencionei na resposta anterior a expressão 'explicitar o conhecimento gramatical'. A ideia é que o estudante detém um conhecimento de língua que se desenvolve na mais tenra idade, no qual está presente um tipo de reflexão. Quem já não viu uma criancinha, no processo de aquisição da primeira língua, demonstrar hesitação, ou um tipo de 'esforço' para produzir uma sentença, uma paradinha para 'pensar' o que vai dizer, como vai pronunciar, que palavra vai escolher...e como é encantador ver as soluções que as crianças encontram, as generalizações que fazem para chegar ao resultado fundamental de produzir um enunciado na sua língua materna e alcançar seus objetivos comunicativos. Os exemplos são inúmeros: '- Eu fazi não!'; A: ‘Tá quente!'/ B: '- Então, diquenta!'; ‘- Que nome é de você?’’. Ocorre que, nesse processo, a criança busca as soluções intuitivamente.

\footnotetext{
${ }^{1}$ O primeiro dado foi coletado pela entrevistada da fala de sua netinha aos 2 anos; o segundo dado é de
} 
Vamos retomar o exemplo ‘Que nome é de você?’. Note que é uma solução 'pensada', e muito bem pensada! Em primeiro lugar, podemos afirmar que essa estrutura não fazia parte do input que a criança recebeu. Certamente, ela deve ter ouvido: '- Como é seu nome?' ou 'Como que você chama?' No entanto, quando foi produzir a sua sentença, a criança 'montou' uma estrutura que recorre ao padrão dos sintagmas de posse em português: O carro do papai/ O papá do nenê/ Os brinquedos das crianças... e então nada mais justo que aplicasse a mesma regra para construir o seu sintagma nominal: O nome de você. E mais, tratava-se de uma pergunta, então montou sua estrutura conforme a regra do português, realizando o termo com pronome interrogativo na primeira posição 'Que nome', mas deixou o restante no final, 'de você', uma operação que demonstra sua intuição 'correta' na tarefa de segmentar o sintagma nominal de posse, embora essa separação não seja abonada na gramática do adulto - ou seja, não estava no input que a criança recebeu. De acordo com a abordagem que adotamos em nossa pesquisa, o conhecimento a respeito da segmentação da estrutura da oração é inato. Esse conhecimento corresponde a uma das noções de gramática, dando conta dessa polissemia a que você se referia na primeira pergunta: é a gramática interna ou mental, o dispositivo de aquisição de língua a que a criança recorre, uma concepção formulada originalmente por Noam Chomsky. ${ }^{2}$

Por essa razão, a tarefa da criança é essencialmente a de alimentar essas unidades sintáticas - a estrutura sintagmática - com os itens lexicais que depreende do input linguístico. Assumindo-se essa visão, nosso entendimento é o de que a educação linguística na escola consiste em explicitar esse conhecimento, pelo desenvolvimento da consciência morfossintática. A razão para adotar esse procedimento está, portanto, no entendimento de que o conhecimento gramatical é intrínseco ao processo de

uma criança de 3 anos e 11 meses, e extraído de C. Mioto et al. (2017) Novo manual de sintaxe. Contexto, São Paulo, p. 43; o terceiro dado foi produzido por uma criança de 2 anos e 7 meses, relatado por uma amiga da entrevistada.

${ }^{2}$ A produção filosófica e científica de Noam Chomsky é extremamente profícua. Para o aprofundamento em relação às bases epistemológicas da abordagem gerativista, refiro a obra Novos Horizontes no Estudo da Linguagem e da Mente, de Noam Chomsky, tradução de Marco Antônio Sant'Anna, Editora da UNESP/ Cambridge University Press, 2005. Adotando o enfoque gerativista na discussão de questões educacionais, remeto o leitor à obra de Lucia Lobato, Linguística e Ensino de Línguas. Brasília: Editora UnB, 2015 [2003]. 
desenvolvimento e uso da língua, sendo essa constatação estendida ao processo de letramento, conforme mencionei. Essa concepção pode ser formulada em termos da hipótese de que o desenvolvimento da leitura e da escrita é comparável ao desenvolvimento de uma segunda língua. ${ }^{3}$ Buscar estratégias para promover a explicitação desse conhecimento na articulação com o processo de letramento é o desafio que temos diante de nós.

Entrevistadores: Dadas as inúmeras divergências de classificações e de definições entre as Gramáticas Normativas e a diversa bibliografia em linguística com muitos resultados empíricos sobre as diferentes variedades do português brasileiro, qual seria, em sua opinião, o caminho mais adequado a ser percorrido pelo professor desde os anos iniciais para ensinar a refletir linguisticamente sobre o ensino de língua materna?

Heloísa Maria Moreira Lima Salles: Creio que, nesse caso, podemos falar de 'caminhos'. Na verdade, o interessante a respeito da metodologia de ensino é que existem muitas formas de implementá-la. Não há limites para a criatividade do professor na formulação de estratégias metodológicas. O que vai fazer a diferença, na minha opinião, são as bases epistemológicas que respaldam as decisões que tomamos na formulação dessas estratégias. E o ponto fundamental para nossa abordagem é o entendimento de que a gramática é intrínseca ao processo de letramento, ou seja, o desenvolvimento da leitura e da escrita pressupõe uma estrutura sintagmática inata, que articula um número finito de unidades ou categorias linguísticas, gerando uma infinidade de expressões a partir de um léxico que compete ao falante utilizar em sua atividade de linguística. Nesse processo, que inclui a leitura e a escrita, depreende-se um atributo essencial, que é a criatividade. No âmbito da gramática gerativa, o conhecimento linguístico inato é também referido como Faculdade de Linguagem, e as operações citadas são, por hipótese, manifestações da gramática universal (GU).

\footnotetext{
${ }^{3}$ A relação entre o desenvolvimento da escrita e a aquisição de segunda língua é investigada em Kato (2005), em termos da hipótese de que esse conhecimento se manifesta como uma gramática periférica, que se caracteriza por reunir estruturas estilisticamente marcadas, por seu uso associado ao registro formal. O texto, intitulado "A gramática do letrado. Questões para a teoria gramatical", está publicado em Marques et al. (orgs.), em Ciências da Linguagem: trinta anos de investigação e ensino, Braga, CEHUM (Universidade do Minho). Investigando também essa hipótese, merece referência a tese de Lílian Pires intitulada Aquisição da escrita padrão do Português Brasileiro (PB) em esfera escolar comparada à aquisição de L2 - a sintaxe do objeto, defendida em 2015, na Universidade de Brasília.
} 
Retomando a questão metodológica, nossa sugestão é que os caminhos a serem trilhados na sala de aula devem partir do pressuposto de que o conhecimento de uma língua natural - no caso, o português -, sendo manifestação da gramática universal, está representado na mente de cada indivíduo/ estudante. É, portanto, um conhecimento individual que propicia a manifestação de dois fenômenos essenciais à atividade intelectual do ser humano, a introspecção e a interlocução. Diante disso, e retomando ideias formuladas originalmente por Lucia Lobato (cf. nota 1), as atividades didáticopedagógicas devem ser voltadas para a explicitação do funcionamento da língua pelo ponto de vista da hipótese da gramática universal (GU).

Naturalmente, o percurso metodológico deve ser formulado em função dos objetivos educacionais, a serem definidos de acordo com as demandas dos estudantes, que incluem questões cognitivas e psicossociais, além das questões relativas ao tipo de conhecimento que se quer explicitar. O desenvolvimento acadêmico incluirá atividades de reflexão acerca das estruturas linguísticas sistematizadas por procedimentos de problematização. A problematização, por sua vez, será feita pelo confronto sistemático de dados da língua, o que permitirá a eliciação das propriedades formais das estruturas envolvidas. Esse procedimento está ilustrado em um artigo que publiquei, em 2011, em coautoria com colegas da Universidade de Brasília, Eloisa Pilati, Rozana Naves e Helena Guerra Vicente. ${ }^{4}$ Com a abordagem por procedimento de eliciação na investigação de cada problema colocado ao estudante, acreditamos ser possível promover a aprendizagem ativa das propriedades linguísticas relevantes, sendo a noção de aprendizagem ativa entendida no termos de Pilati (2017). ${ }^{5}$

\footnotetext{
${ }^{4}$ PILATI, Eloisa. NAVES, Rozana; GUERRA VICENTE, Helena; LIMA SALLES, Heloisa. 2011. Educação linguística e ensino de gramática na educação básica. In. Linguagem e Ensino, v.14, n.2, p.395-425, jul./dez.

${ }^{5}$ Segundo E. Pilati (2017), na obra intitulada Linguística, gramática e aprendizagem ativa, publicada pela Editora da Universidade de Brasília, a educação linguística deve promover a aprendizagem linguística ativa, definida nos temos de Bransford et al. (2007), a partir dos seguintes requisitos: I) considerar o conhecimento prévio do aluno; II) Desenvolver o conhecimento profundo dos fenômenos estudados; III) Promover a aprendizagem ativa por meio do desenvolvimento de habilidades metacognitivas. Não temos como aprofundar a interessante discussão, nos termos propostos pela autora, ficando a referência para os leitores; no entanto, é possível verificar que os pontos citados vêm ao encontro de nossas ponderações.
} 
Entrevistadores: Considerando a introdução/ inserção da Linguística como disciplina no componente curricular dos cursos de Graduação de boa parte das Universidades brasileiras tanto de Letras, como mais recentemente de Pedagogia, de que forma você avalia a apropriação dos conceitos emanados da linguística pelos profissionais da Educação Básica?

Heloísa Maria Moreira Lima Salles: A afirmação de que os profissionais que atuam na Educação Básica devem se apropriar dos conceitos emanados da linguística quase soa como um truísmo. No entanto, é preciso explicitar as condições que vinculam os próprios conceitos da linguística aos objetivos da Educação Básica. Parece que a explicitação é uma palavra de ordem, não é? Creio que a retomada desse termo no contexto da formação de professores nada mais é do que a replicação em um nível acadêmico mais avançado do que foi dito anteriormente. É quando reconhecemos que o debate acerca das bases científicas dos conceitos da linguística, no âmbito das licenciaturas, é essencial à formação do profissional. O acesso a esse debate é uma maneira de verificar como se dá a problematização de vários fenômenos, tendo em vista as exigências do método científico. Dessa forma, espera-se que a formação profissional contemple a revisão do estado da arte em diferentes campos da linguística, com as implicações quanto ao debate epistemológico, por um lado, e quanto aos diferentes níveis de análise e de arranjos temáticos, por outro. Claro que não será possível esgotar tais temas, até porque na ciência esse verbo não é conjugado, não é? Haverá sempre novos fatos, novos problemas e novos enfoques a buscar. A questão é o que abordar, diante das demandas colocadas ao professor na sala de aula.

Neste ponto, é importante ressaltar a relevância dos estudos na área de linguística textual, a partir do entendimento de que o texto é a unidade de análise para a educação linguística em contexto educacional. De fato, pode-se dizer que já existe um consenso em relação a essa questão. No entanto, esse entendimento não pressupõe a exclusão dos estudos gramaticais, como foi - e tem sido - defendido por alguns linguistas. Do reconhecimento do texto como unidade de análise ao abandono dos estudos da gramática vai uma distância muito grande, que repercute inclusive na formação dos profissionais, pois em alguns ambientes acadêmicos, a formação em teoria gramatical é excluída sumariamente, deliberadamente dos currículos. Chega a ser uma questão ética subtrair essa formação, sob o argumento de que não será 'útil' no contexto da Educação 
Básica. Um atributo inerente da linguagem humana, que é a estrutura gramatical, ser ignorado ou subtraído da formação é imperdoável.

Assumindo-se a relevância do estudo da gramática pela perspectiva ora proposta, é indispensável promover o acesso a essa formação, de forma consistente e efetiva. Nesse aspecto, a relevância da abordagem da gramática gerativa é inegável, pelos resultados alcançados, que têm confirmado as hipóteses, pela capacidade de abranger fenômenos distintos, em diferentes línguas, pelas possibilidades de interface com outras áreas do conhecimento, especialmente em relação à neurociência, à psicologia cognitiva, à psicolinguística, à educação, entre outros campos.

A abordagem científica dos fenômenos linguísticos tem ainda a importante consequência de propiciar o entendimento da variação linguística, por um lado, e a desmistificação da norma padrão, por outro. A partir dessa apropriação, a escola passa a contar com a atuação de um professor que não mais se submete ao dogma da norma, passando a entendê-la pelo ponto de vista dos usos linguísticos, e não mais como a única forma de expressão que 'merece' ser aprendida, o que historicamente fomentou o preconceito linguístico em nossa sociedade. É claro que existe uma distância entre ter o entendimento de que essa visão da norma padrão não se sustenta e ter uma prática que contemple essa visão. E então retornamos ao que foi dito anteriormente.

Entrevistadores: Considerando as orientações dos PCNs de Língua Portuguesa de que é papel da escola desenvolver as habilidades de oralidade, escrita e leitura em diferentes contextos sociodiscursivos, você percebe se tais habilidades vêm sendo contempladas na Educação Básica no que se refere especificamente ao ensino de Gramática empreendido?

Heloísa Maria Moreira Lima Salles: É difícil fazer uma afirmação a esse respeito, considerando a amplitude do sistema educacional em nosso país - e mesmo na região em que atuamos. O que podemos afirmar é que os indicadores educacionais apontam para a existência de grandes fragilidades no ensino de língua, notadamente em relação ao trabalho com a língua portuguesa na escola. São frustrantes os resultados em exames nacionais. São evidentes as dificuldades do estudante que chega à Universidade, o que nos remete à educação linguística oferecida na escola. Naturalmente, esses indicadores 
não captam outras variáveis em relação ao desempenho do estudante, o que inclui questões sociais, econômicas, afetivas, que se traduzem em escolas precárias, falta de professores, baixos salários dos profissionais da educação, falta de equipamentos educacionais, desemprego, desagregação familiar, entre outros fatores. Poderíamos nos estender muito na análise dessa questão, mas acho que a conclusão aponta para a necessidade de promover um grande debate sobre a formação de professores e sobre os currículos de letras, particularmente em relação ao professor de língua portuguesa, se desejamos buscar alternativas a essa situação, que façam efetivamente a diferença.

Entrevistadores: Como correlacionar aspectos teóricos, didáticos e metodológicos no que diz respeito ao ensino de gramática do português brasileiro para crianças/adolescentes que estão em situação de aprendizagem de L2, como é o caso de sinalizantes de línguas de sinais como LIBRAS, por exemplo?

Heloísa Maria Moreira Lima Salles: Essa pergunta é tão difícil quanto as demais, mas é igualmente relevante, e como as demais, demonstra o preparo cuidadoso da entrevista pela editoria da Revista. Agradeço muito por esse trabalho dedicado e profissional, que me convida a refletir sobre questões que têm motivado minha pesquisa e minha atuação profissional, sob pontos de vista e recortes extremamente interessantes!

Chegamos então a este ponto, em que constatamos que existe uma situação de bilinguismo/ multilinguismo na sociedade, considerando-se, por um lado, o aspecto dialetal, definido pela perspectiva da sociolinguística, e por outro, a existência de comunidades em que o português é segunda língua, como no caso dos surdos, e de outros grupos, como as nações indígenas, e aqueles que chegam ao país como imigrantes - lembrando dos fluxos migratórios que ocorrem neste momento, motivados por questões políticas e econômicas graves, e também daqueles que ocorreram no passado, com implicações para a formação de nosso país e de nossa sociedade. Isso nos faz constatar que educação linguística deve ter como referência essa realidade e dela decorrem consequências de grande impacto cultural e social. Em relação aos surdos, podemos afirmar que tudo que foi dito até o momento se aplica à educação linguística dessas pessoas, com as devidas ressalvas. 
Considerando as condições perceptuais dos surdos, partimos do pressuposto de que a Língua Brasileira de Sinais (LIBRAS) é a primeira língua, e o português (escrito) a segunda língua dessas pessoas. Considerando o papel primordial da escrita, já que a modalidade oral não está disponível, caberá desenvolver uma metodologia específica, baseada na pedagogia visual. ${ }^{6}$

Fica, portanto, evidente que as decisões em relação a esse grupo envolvem variáveis específicas... No entanto, do ponto de vista da abordagem que adotamos, haverá alguns aspectos que permitirão um olhar consistente com o que foi dito até o momento. Crucialmente, destaco a natureza do conhecimento linguístico. Apesar de haver diferenças importantes em relação à modalidade utilizada, visual-espacial, no caso da língua de sinais, e oral-auditiva, no caso do português, a abordagem da gramática gerativa parte do entendimento de que o falante detém um conhecimento linguístico inato, sendo a LIBRAS, no caso, adquirida como primeira língua, nas mesmas condições descritas para a aquisição do português (ver nota 4). Diante disso, assumimos a hipótese de que o desenvolvimento do português (escrito) (e da leitura) constitui um tipo de aquisição de L2, ainda que, diferentemente do que ocorre com o estudante que tem como L1 uma variedade dialetal do português, o processo envolve línguas muito distintas. No entanto, pelo ponto de vista da gramática universal, é possível identificar essas línguas, no que se refere à estrutura sintagmática e às categorias gramaticais envolvidas. Nesse sentido, pressupõe-se a existência de um conhecimento linguístico prévio (a L1), o qual corresponde ao estado mental inicial, sendo o desenvolvimento da $L 2$ determinado pelo acesso ao input linguístico da língua alvo (sempre na modalidade escrita). Esse processo propicia o surgimento da interlíngua, que manifesta fases, de acordo a natureza e as condições do acesso a esse input.

Retomando os termos da pergunta, fica então evidente que esse entendimento estabelece parâmetros para as decisões relativas às estratégias metodológicas. Se entendemos que as línguas compartilham propriedades formais, e se assumimos que as

\footnotetext{
${ }^{6}$ As questões que cercam a educação de surdos têm sido discutidas amplamente. Em relação à pedagogia visual, considerando os aspectos inerentes à aquisição de língua, por um lado, e as questões metodológicas, por outro, ressaltamos a contribuiçãoo pioneira de Ronice M. Quadros, na obra Educação de Surdos: a aquisição da linguagem. Porto Alegre. Artes Médicas, 1997.
} 
diferenças translinguísticas são epifenômenos, é possível promover a explicitação dessas propriedades, a fim de alcançar os objetivos que citamos anteriormente. Esses pressupostos têm sido adotados em estudos que investigam as características da interlíngua do surdo na aquisição de português L2 (escrito), com resultados muito interessantes, que podem subsidiar a formulação dos projetos educacionais voltados para ensino de português L2 (escrito) para surdos na Educação Básica. ${ }^{7}$

Conforme mencionei, não há limites para os caminhos que se pode trilhar na tarefa de propor atividades didático-pedagógicas que promovam a explicitação do conhecimento gramatical, como requisito para o desenvolvimento da leitura e da escrita no contexto educacional. Imprescindível, portanto, é reconhecer - e conhecer! - o papel das propriedades gramaticais no desenvolvimento linguístico e, por consequência, sua relevância para a educação linguística.

Nesse trabalho fascinante, pressupõem-se políticas de Estado compatíveis com as demandas da educação nacional, que incluem a formação adequada dos profissionais, investimentos na carreira e nos equipamentos educacionais, além do apoio da sociedade, em particular no que se refere à relação entre a escola e a família. Finalmente, e não menos importante, é preciso contar com o engajamento do professor e com a mobilização dos estudantes na busca do conhecimento e na descoberta de caminhos sempre novos para a realização das atividades acadêmicas. No mais, é estudar muito, pois escola não é lazer, mas também não é lugar de sofrer, é lugar de prazer, prazer em aprender!

\footnotetext{
${ }^{7}$ Adotando essa abordagem, citamos estudos realizados no âmbito da Universidade de Brasília: A. Mesquita (2008) A categoria preposicional na interlíngua do surdo aprendiz de português L2. Dissertação de Mestrado, UnB; Lima-Salles H. M.; Naves, R. R. (Orgs.) Estudos gerativos de língua de sinais brasileira e de aquisição de português (L2) por surdos. $1^{a}$. ed. Goiânia: Cânone, 2010.; Lima-Salles, H. M. L.; Vianna, A. C. Estudo da interlíngua de surdos usuários de Língua de Sinais Brasileira na aquisição de português (L2): nominais nus e definidos genéricos. Estudos da Linguagem. 8(1), 241-264. $<$ http://www.estudosdalinguagem.org/seer/index.php/estudosdalinguagem/article/view/181/264>; Salles, H. M. M. L.; L. Pires (2011) Desenvolvimento linguístico na aquisição de português L2 (escrito) por surdos: a estrutura do sintagma nominal. Revista da ABRALIN, v. 1, p. 189-208. <http://abralin.org/site/revistaabralin/edicoes-anteriores/2011-vol-especial-10-parte>.
} 
